\title{
Factors Related to the Willingness of Employees to Accept Telecommuting: Preceding the Pandemic Crisis
}

\author{
Lucila Patricia Cruz Covarrubias \\ Universidad del Valle de Atemajac (UNIVA) \\ Sistema Nacional de Investigadores (SIN) \\ Universidad de Guadalajara \\ Pedro Aguilar Pérez \\ Universidad de Guadalajara \\ Pedro Daniel Aguilar Cruz \\ Universidad de Guadalajara \\ Aurora Araceli Carbajal Silva \\ Universidad de Guadalajara
}

The purpose of this paper is to determine the factors that affect the willingness of employees to adapt to telecommuting and determine the feasibility of implementing this in Mexican organizations. A sample of 384 employees from different companies established in Guadalajara City was used to analyze the perception of attitudes, capabilities, and advantages of performing their tasks from home. The results show that participants agreed on the time they would be willing to work from home, as well as the wages, capabilities, skills that employees should have to be able to develop telecommuting and the advantages that this scheme would represent. There is a great concern about this scheme among employees since they agree that telecommuting should be applied to company managers and not for subordinates. The topic is emerging in companies and there is currently a great opportunity to implement telecommuting. SMEs use flexible work practices and there is a possibility that it can be advantageous all members of the organization.

Keywords: telecommuting, employees, work culture, work practices

\section{INTRODUCTION}

Telecommuting, although a modality of recent presence in Mexico, has a few important references of its development. The security software company, Avast, highlights that only 2 out of 10 economic units have the requirements to work from homophile $81 \%$ of workers do not get the technological support required for telecommuting. The limitations that economic units in the country have to carry out this work at home model consist of the lack of organization, training and virtual infrastructure, as well as the lack of confidence in employees to do Home Office (Camargo, 2020). 
According to statistics from the National Statistics and Geography Institute (INEGI), the 2018 economic census found that only $20.4 \%$ of the total number of economic units in Mexico have used connectivity and the development of Information and Communications Technology (ICT) in their production processes. Micro-enterprises (0-10 employees), are the ones that face difficulties to continue with their operations due to the impossibility of connecting with their customers, when unexpected events appear, since $78.8 \%$ of these companies do not have the connectivity chain and technological equipment necessary to carry out their operations during the closing of the business (INEGI, 2019).

The purpose of this study is to analyze the evaluation that administrative employees have of telecommuting, as well as to determine factors that influence the adoption of this modality of work.

The question that focuses this research is posed as follows: what are the factors, practices and organizational commitment that affect the willingness of administrative employees to adopt telecommuting?

The importance of the study is to consider telecommuting as an option in crisis times, to understand opportunities for change, innovation, and improvement in the quality of life of the people involved in the organization and of course of society.

\section{LITERATURE REVIEW}

As part of the telecommuting literature, Peros Khan et al., (2018), find Kurland and Bailey (citation details?), as pioneers of the concept, who point out that this work modality provides opportunity to improve work performance with latently beneficial effects for the employer, the worker and society as a whole. This is due to the greater work practice flexibility that employees experience regarding where and when they work. They can decide the time, methods and place to perform the task, improving their productivity. The motivation and benefits of telecommuting must be seen in the context of improving organizational processes. Other researchers report that teleworkers experience four usual potentialities when they admit the labor convention of telecommuting, which are: job autonomy, work-family balance, work productivity, and occupational stress levels (Cicei, 2015; Kundaragi and Kadakol, 2015; Raffaele and Connell, 2016).

Telecommuting is a means of accomplishing employee tasks with a degree of freedom and autonomy. Several studies reviewed, published by the American Psychological Association (APA), mention that in 46 researches where 12,833 employees were involved, they find that telecommuting has overall beneficial effects including, for example, more control of their work, autonomy, job satisfaction, more commitment to the company, less stress, better work-family balance, and higher performance ratings by supervisors (Peros Khan et al., 2018).

Meanwhile Neirotti et al., (2019), point out that another study performed in Peninsula Malaysia, shows that $90 \%$ of male workers and approximately $85 \%$ of female employees indicated that job autonomy influences job satisfaction and performance. Psychologically, this motivates employees to perform their work tasks more efficiently and clearly transfers to higher performance. In fact, employees tend to be happier when performing work tasks if they have control over their work time, space and means to fulfill their duties. Moreover, creativity is not limited because the labor authority is not nearby.

Peros Khan et al., (2018) provide a Dutch report where it was disclosed that the time period dedicated to children has become more and more appreciated by parents who have to do telecommuting, where free time has become more and more appreciated. Telecommuting greatly supports flexibility in terms of time and place. Working parents have greater time flexibility, as they save on travel time to the company, allowing them to care for their children or other family members and, at the same time, perform work tasks at home. In addition, they reveal less interference between work and family roles, leading the researchers to conclude that teleworkers may be better able to manage some key aspects of work-family conflict. Greater flexibility in the boundaries of telecommuting can help employees regulate and synchronize work tasks and individual needs, and potentially reduce work-family conflict (Cicei, 2015).

Other more extensively perpetuated studies are the one conducted by the United States Economic Council in 2010, which was conducted in more than 700 companies in various countries (UK, USA, France 
and Germany) where they found "significant relationship between work-life balance labor practice and total factor productivity" (Kossek and Michel, 2014, p. 4).

On the other hand, the literature reports that to successfully implement telecommuting it will be necessary that the company meets a minimum of technological and organizational requirements, "since an organization with inadequate technology would lead teleworkers to experience an interrupted and consequently unproductive work process" (Tapasco Alzate and Giraldo García, 2016, p. 89). Organizations adopting telecommuting face three main technological challenges: connectivity, information transfer and communication (Pearce II, 2009). Similarly, Davies (2013) reports that people are reluctant to adopt telecommuting when there are inadequacies in the resources requested, since the effectiveness of telecommuting demands equipment and software in higher quality and quantity.

Beham, Baierl and Poelmans (2015) point out that there are two factors directly related to the work performed under the telecommuting modality: "the contextual ones, which refer to the corporate culture, thoughts and family environment, and the formal ones, related to the work performed in the organization, increasing profits" (p. 11). According to the International Labour Organization (ILO), it exposes that workers are more efficient when telecommuting is adopted as a work modality, because general costs can be reduced by up to $85 \%$ and productivity can be increased by $30 \%$ (Guzmán Duque and Abreo Villamizar, 2017). In addition, in a study carried out in Mexico, it was shown that absenteeism was directly related to the health of workers and, that, through telecommuting, the worker's productivity could be increased, in the performance of their duties (García and Martínez, 2016).

The research by Raffaele and Connell (2016) focused on exploring how telecommuting can contribute to or detract from individual and organizational flexibility, as well as the range of advantages and disadvantages that telecommuting can offer. The research seeks to identify whether employees can predict the acceptability of taking work activities home. As shown in the literature review, telecommuting implies, for the workers, a series of advantages, as well as organizational and individual commitments. Specifically, the individual characteristics, the advantages for the worker, and the company's commitment are three variables that can be analyzed to reduce resistance towards accepting this type of distance work, which is why they are incorporated into this research as independent variables.

According to Giniger (2020), in contrast to research that points out the benefits and advantages of telecommuting, a massive move to work at home is not the most optimal since most organizations do not take care of the expenses and work tools, which are assumed by the workers, "which, obviously, implies a salary reduction" (p. 32).

Although many media spread that teleworkers "spend less", it is an imaginary broadcast, since, internet services, energy, maintenance and other essential services, expenses that are commonly covered by the company (sometimes food), in telecommuting are on behalf of employees (Giniger, 2020).

Using this same perspective, Cifuentes and Giraldo (2017) mention that in telecommuting is remarkable the employee's responsibility for activities that were previously carried out by the employer. The author also adds that, in addition to the work overload, there is a recognized isolation at work, which leads to privileging production over socializing with co-workers. The space-time distancing of workers "hinders the organization of work/social life, teamwork, promotion conditions; wages decrease... But, in addition, not moving brings negative consequences to physical and psychological health" (Giniger, 2020, p. 33).

In the literature previously described, it is clear that the main factors that influence the implementation and development of telecommuting are related to human and organizational factors rather than technological elements, without excluding the importance of other factors such as trust, work autonomy and technological infrastructure necessary for the implementation and practice of telecommuting.

\section{METHODOLOGY}

The research employs a quantitative approach. It was decided to make surveys to employees of different companies. To collect the information, it was taken into account that they were workers in different administrative positions (area managers, marketing, human resources, accounting, finance, sales, etc.) and that they were working during the period in which the study was carried out (February-March 2020). As 
Hernández Sampieri et al., (2014) point out, "it seeks to specify the properties, characteristics and profiles of people, groups, communities, processes, objects or any other phenomenon that is subjected to analysis" (p. 92).

In order to determine the number of surveys to be conducted, it was decided to work with a confidence level of $95 \%$ and a significance level of $5 \%$. For determining the sample size, we used the equation established by Lind, Marchal and Wathen (2015) who argue that when the population is unknown or exceeds 10,000, the formula is as follows:

$\mathrm{n}=\frac{\mathrm{Za}^{2} \times \mathrm{p} \times \mathrm{q}}{\mathrm{d}^{2}}$

Therefore, the sample consisted of 384 employees working in companies established in the metropolitan area of Guadalajara (AMG) ${ }^{1}$, companies such as: IBM, Mega Cable, WIZELINE, DomerCall Center, Honda, Alestra, among others. The age range of respondents was between 17 and 55 years old.

The instrument that was applied contains 20 questions, which were grouped into three dimensions: Individual characteristics; aptitude towards telecommuting, and organizational aspects. For the measurement of some variables, the items were established on a Likert scale from 1 to 10 , where 1 corresponds to the "most important" and 10 refers to the "least important". Multiple-choice questions were used for demographic and general job variables.

The data obtained were processed in the SPSS V.25 program, after creating a database in Microsoft Excel 2016. The results were displayed in statistical tables with absolute and relative percentage frequencies assigned to the values of the variables, as well as figures to facilitate their interpretation. To measure the reliability of the instrument, the Cronbach's Alpha test was applied, which relates the variables and establishes the reliability of the questionnaire, yielding a value of 0.81 , established as good for an instrument to be reliable (Díaz, 2002).

\section{PRESENTATION OF RESULTS AND DISCUSSION}

Of the total number of respondents, $52.6 \%$ have been in their jobs for 1 to 5 years, $19.3 \%$ less than one year and the rest have more than 5 years of seniority. The results show that $66.7 \%$ of the respondents stated that their physical presence in the company is necessary to perform the tasks in the job they perform, and $33.3 \%$ stated that their physical presence in the organization is not necessary. Although the majority answered yes to the presence of the employee in the organization, this differs from the percentage concerning the question "Would you be willing or would you like to work from home?" Figure 1 shows the following results: $74 \%$ stated that they would like to work from home and the remaining $26 \%$ stated that they are not willing to work from home. Regarding the willingness to telecommute, we proceeded to filter this with some other variables that show statistical association, through the chi-square test of independence, selecting those with p-values less than 0.1. The results reveal that almost none (except for age) of the variables associated within the individual aspects showed statistical association with willingness to telecommute. Specifically, neither gender, nor seniority at work, nor level of schooling, nor marital status showed a relationship with the willingness to adopt telecommuting, but the degree of autonomy and flexibility of schedule perceived by workers. 


\section{FIGURE 1 \\ WILLINGNESS TO ACCEPT TELECOMMUTING}

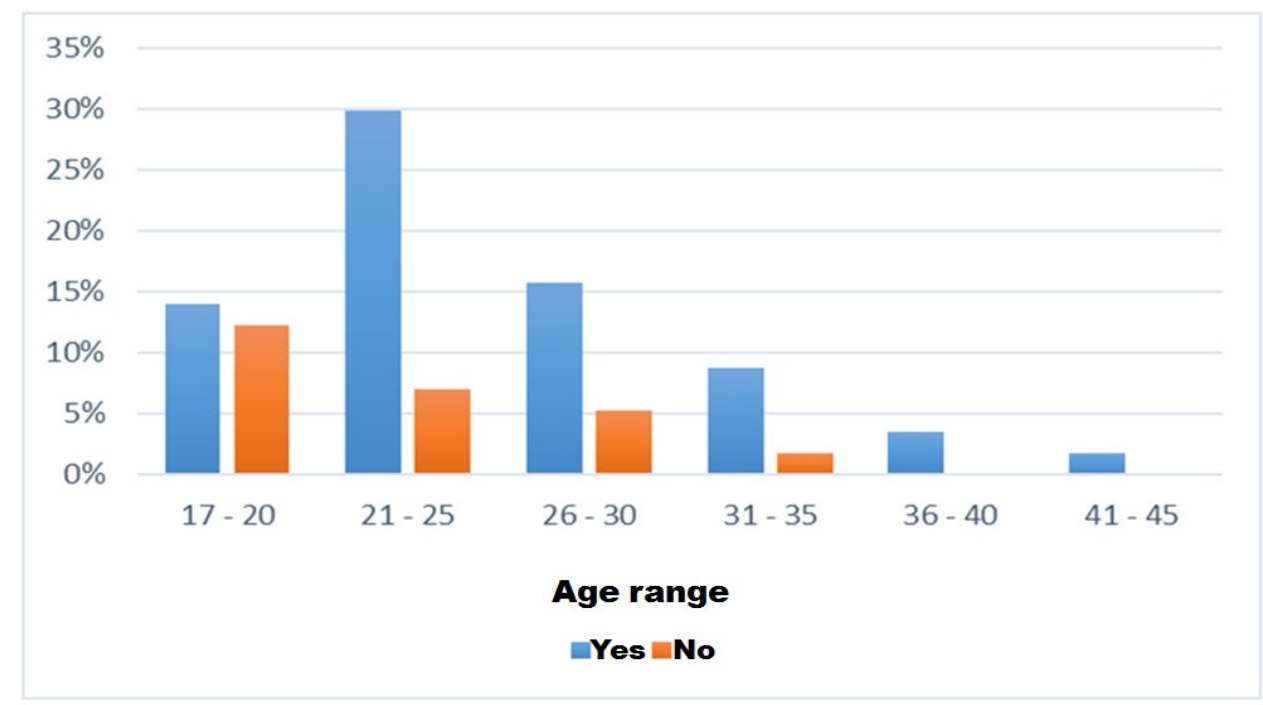

Source: developed by the author

In relation to the above, the employee likes to work from home because he/she determines several advantages, since the participants state as an advantage to work from home (for convenience (33\%), for cost savings (21.5\%), and $45.5 \%$ to have more time to perform other activities). Figure 2 shows these results by marital status, showing big differences in terms of cost savings, since married people see the savings they would have from working from home as a greater advantage. Likewise, there is a big difference in the "comfort" variable, where singles perceive it as staying at home.

Similarly, to the study conducted by Peros Khan et al, (2018); and Neirotti et al, (2019), the study has shown that work autonomy, control over their work time, work flexibility and cost and time reduction allows employees to experience benefits to accept telecommuting as a work modality.

\section{FIGURE 2 EMPLOYEE BENEFITS OF WORKING AT HOME}

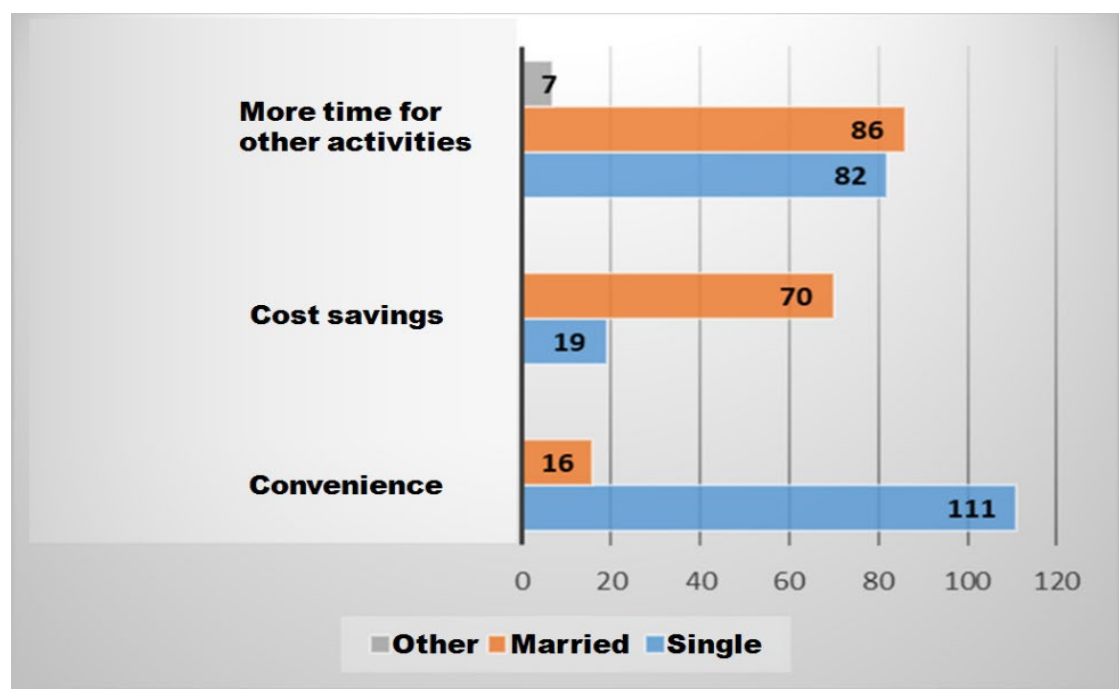

Source: developed by the author 
Regarding the question What would be the conditions you would request in order to work from home? Figure 3 shows that the highest percentage (31.1\%) corresponds to respecting working hours, followed by $28.9 \%$ indicating that the company provides a good Internet connection, $17.8 \%$ revealed that they have the technological tools to perform their work, followed by $8.9 \%$ indicating comfort and a good salary, and only $4.4 \%$ that they work on a project basis. It is important to note and take into consideration that $60 \%$ of the participants have the view that, if the company implements this type of work, working hours would not be respected and that they would probably not be provided with internet (paid for by the company) at home.

\section{FIGURE 3 \\ CONDITIONS FOR WORKING FROM HOME}

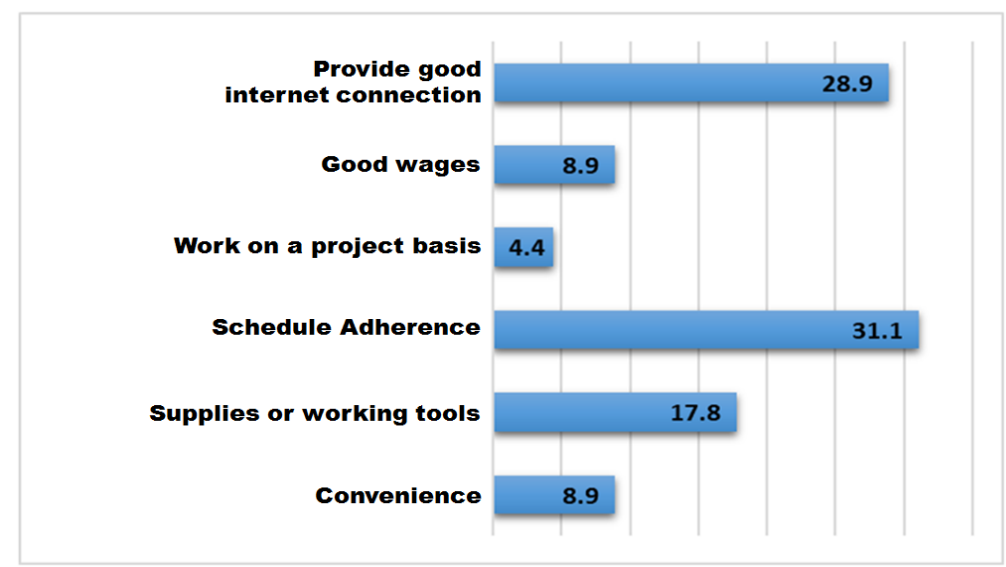

Source: developed by the author

Although in the previous figure (No. 3) benefiting from a good salary as a condition for working from home was not significant (only $8.9 \%$ of the participants indicated this). On the other hand, when asked: would you be willing to sacrifice a percentage of your salary or benefits in exchange for working from home? Figure 4 indicates that $85.4 \%$ would expect to receive the same salary they currently receive. Approximately $10 \%$ stated that they would not expect to receive the same salary, even stating that they would expect between $10 \%$ and $20 \%$ more. Only $4.9 \%$ are willing to reduce their salary by $20 \%$ to $30 \%$ to work from home.

\section{FIGURE 4 \\ WILLINGNESS TO HAVE LOWER SALARY OR BENEFITS FOR WORKING FROM HOME}

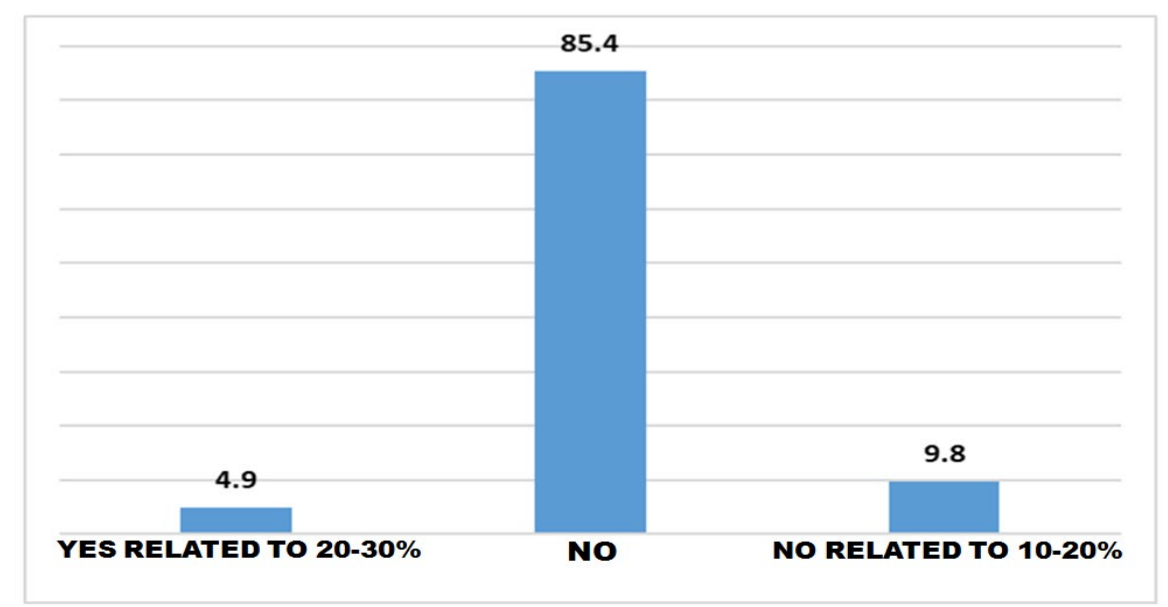

Source: developed by the author 
Regarding the disadvantages of telecommuting, $36.8 \%$ of respondents said that a disadvantage would be the lack of communication or distortion of it, of which $56 \%$ would be willing to do their work from home, versus $42 \%$ who said they would not be willing to work from home. $31.6 \%$ of the respondents stated that another disadvantage would be the possibility of not having the same level of concentration at home to perform the work, of which $60 \%$ would be willing to work from home while $48 \%$ would not be willing to do telecommuting. About $24 \%$ of employees felt that another disadvantage would be to enter a "comfort zone" and become sedentary in the way they do their work, because they argue that there is no direct supervision (visual control) from managers and too much autonomy in decision making would be detrimental to the efficiency of performance.

Regarding the culture in Mexico concerning this work model, $87.5 \%$ stated that there is no culture of telecommuting, of these $48 \%$ would be willing to telecommute, while $52 \%$ would not be willing to do so.

Only $38.6 \%$ of the participants indicated that the company where they work has the culture to implement this work scheme, of which $61 \%$ would be willing to work from home while the remaining $39 \%$ would not like to telecommute. The highest percentage of respondents $(61.4 \%)$ felt that the company where they work does not have the culture to perform telecommuting, of those who thought so, $79 \%$ would be willing to do their work from home (see Figure 5). These results, where most of the participants answered that where they work there is no culture of telecommuting, we can deduce as follows: a large percentage of all respondents (48.2\%) perform several tasks in the company, from a good management of computer applications, management of communication channels (email or social networks) to management of administrative tasks, therefore they require electronic platforms, space and maximum communication between company-customer-management for problem solving. This is in line with the results obtained from item 11, where the question "In which positions do you think it would be feasible to start with this work scheme in your company? $72 \%$ considered it feasible to start in executive or management positions."

\section{FIGURE 5 \\ TELECOMMUTING CULTURE IN MEXICO}

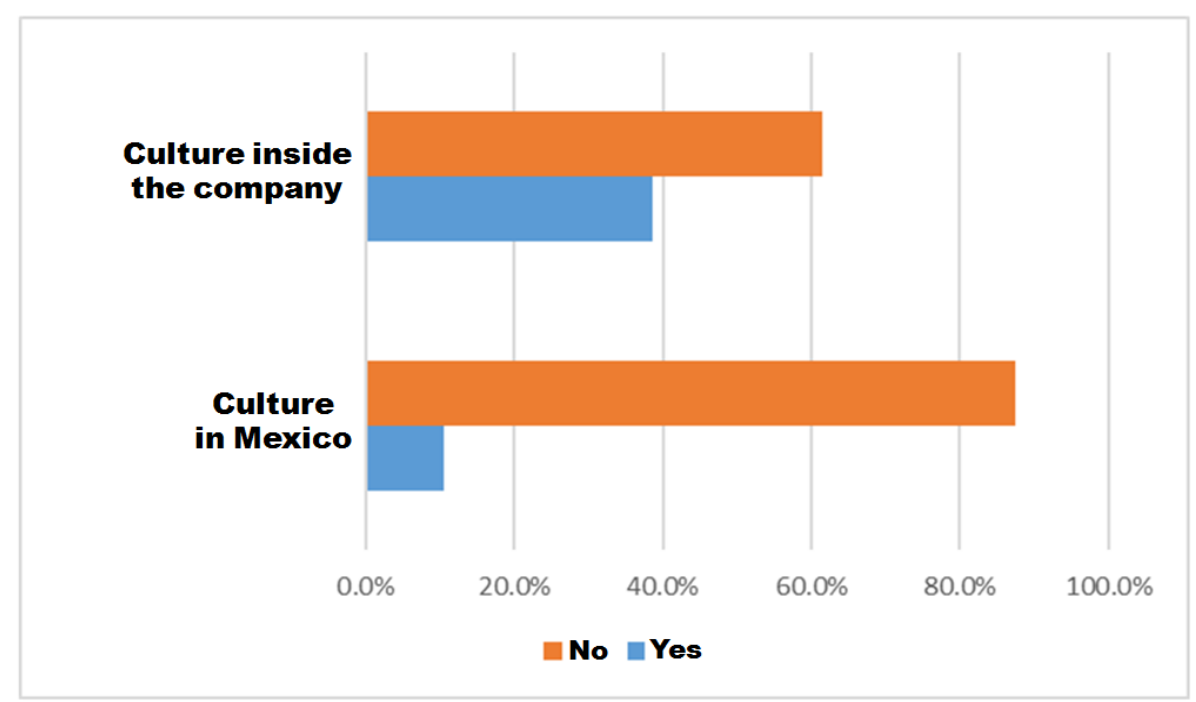

Source: developed by the author

Regarding the main characteristics that employees should have to perform the work at home, in relation to which they were asked to select ten personal qualities that they think they should currently have in order to be able to perform telecommuting, respondents considered as the first characteristic, the management of simultaneous tasks $(70.2 \%)$, followed by the domain of ICT's $(66.7 \%)$, as a third choice they selected that they should be organized (63.2\%), followed by self-motivation (61.4\%). In Figure No. 6 we can check these 
characteristics that they considered for telecommuting. It is important to highlight that "responsibility" is not among the top ten qualities or capabilities mentioned, as it received only $35.1 \%$ of the votes.

Regarding the aforementioned, it can be concluded that the characteristic of "responsibility" belongs to the management levels, because telecommuting requires a strong degree of commitment with the organization. This finding confirms what was pointed out in the change management theory (Madero Gómez and Flores Zambada, 2009), where it was shown that in the hierarchical levels there is a greater willingness to accept telecommuting, due to the commitment they have with the company.

\section{FIGURE 6 \\ EVALUATION OF WORKERS' SKILLS FOR ADOPTING TELECOMMUTING}

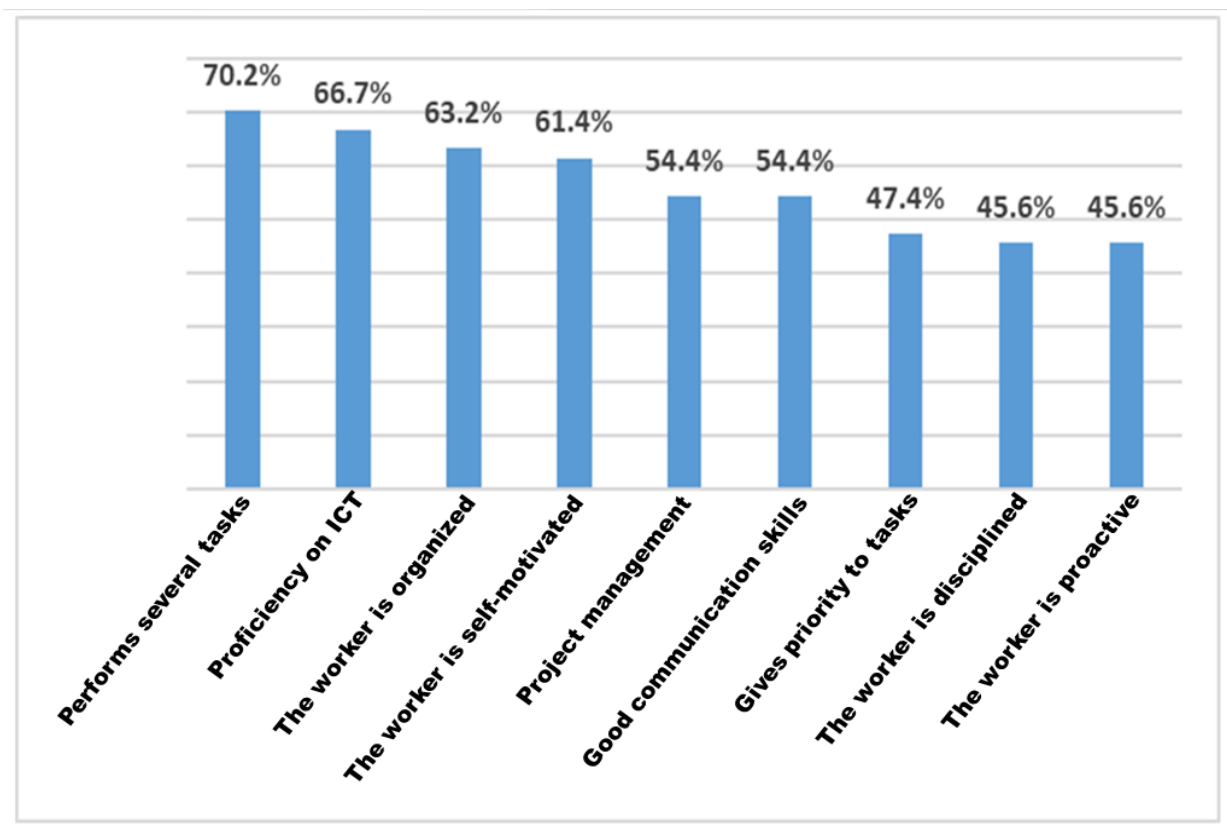

Source: developed by the author

Concerning the results on what skills do the workers surveyed appreciate in order to adopt telecommuting, bivariate correlations were made between the competences, and it was discovered that the management of simultaneous tasks is positively and significantly correlated with the organization of the tasks (W=.913; $\mathrm{p}<.000)$; the domain of ICT's with the communicative skill (W=.876; $<<.000)$, as well as, the discipline with the management of projects $(\mathrm{W}=.868 ; \mathrm{p}<.000)$.

Regarding the "frequency" according to which the participants could do telecommuting, the results show that $45.1 \%$ said that they would be willing to work (from home) from 1 to 2 days per week, 39.8\% would work from 3 to 4 days per week, the rest (15.1\%) would be willing to do telecommuting all week. These results are in line with what Tapasco and Giraldo (2018) report, where they show that flexibility and freedom in working hours lead to the performance of more productive and creative work, contrary to what happens with some workers in regular working hours.

Our results contribute to the telecommuting and participation literature in several ways. First, the study progresses in the theory of telecommuting by identifying how this modality is beneficial for the well-being of employees (see García and Martínez, 2016), we argue that the availability, flexibility of working hours and doing it from home, is really beneficial especially in times of health crisis.

This research also contributes to the literature on teleworker outcomes, such as that by Peros Khan et al., (2018) who find positive effects of this new work format on employee performance in the oil and gas industry in Kuantan; Neirotti et al, (2019) who find that adopting telecommuting can have positive effects on increasing work engagement through greater worker autonomy and access to telecommuting, and in 
Guzman Duque and Abreo Villamizar (2017), where they find a positive relationship between telecommuting and organizational competitiveness.

The research shows that telecommuting is directly related to organizational commitment, if the employee is assisted, either by improving or respecting work perceptions will influence the employee's commitment. This is consistent with the COR theory that the company is concerned with the employee's work and family well-being, which has an influence on increasing commitment and developing a positive attitude towards the company. For these reasons, telecommuting can be an effective alternative work plan to adopt, especially in difficult times, with the commitment and participation of employees.

The results of this research show that telecommuting is a modality that favors employees, especially in stressful situations, such as the health crisis that we are currently experiencing. It will be necessary to know the perception of the businessmen in the Guadalajara Metropolitan Area regarding this new modality, if it is accepted for its permanent implementation or if it is only temporary (as long as we are in the Covid-19 pandemic).

As well as demonstrating the acceptance of telecommuting by employees, there are also obstacles to its implementation as a labor alternative, it is questioned the lack of knowledge about telecommuting both employers and teleworkers, the lack of technological resources at home. Similarly, the corporate culture indicates that there is a lack of trust in the employee's work performance, and a need for the manager to control the subordinate's tasks.

Regarding technology, some research shows that there is inequality among people in terms of technological resources, showing that the availability and access to the Internet has a large statistical spread (Ruiz, Gonzales and Lucendo, 2020).

\section{CONCLUSIONS}

The coronavirus pandemic, immediately forces the implementation of telecommuting in all economic sectors in greater or lesser intensity. This is a working method imposed by the authorities and ceases to be an internal option for many companies regarding organization. In Mexico, this new working modality is in the regulation process, which is still open, but, above all, it requires a change of organizational and social culture.

There is a positive perception towards telecommuting participation, especially in terms of work flexibility, work-family balance and occupational stress on employee performance. The adoption of telecommuting is relevant to help the employee, society and the country to have a social distancing in this time of health crisis due to COVID-19 and ensure their health and welfare and this leads to better performance of employees. However, telecommuting participation may not be suitable for everyone. It is only appropriate to be performed by certain positions and work sectors, such as the employee who performs administrative, marketing, decision-making, academic, telecommunications and information technology activities. In addition, there is a gap among Mexico's workforce that leads to resistance in accepting telecommuting.

Therefore, the results found in this research study cannot be applied to all sectors due to the difference in culture, work style and economic level. It is necessary to consider that organizations perform more indepth studies on the jobs that would be more feasible to implement telecommuting.

Another of the research findings is that employees value in different levels the advantages of telecommuting, highlighting the cost savings, more time to perform other activities and the convenience of working from home, while the option that showed a lower number of positive responses was the alternative of obtaining another job, concluding that there is a willingness of employees to work from home.

In summary, the telecommuting scheme in Mexico, requires the provision of skills, qualities and competencies, related to self-discipline, self-motivation, perseverance, organization, responsibility and commitment, so that telecommuting, at the enterprise level, involves several transformations, adjustments and changes in the organizational culture that are significant for the effective performance of the work through the use of technologies and social and virtual networks of high complexity. 
In the literature reviewed, it was found that telecommuting generates damages to the employee, some of them irreversible, causing social isolation, poor working relationship, due to lack of regulation, low wages and violations of labor rights, economic profitability for organizations; stress, anxiety and depression due to digital slavery and inseparable scenarios of work and family or personal environment.

This research suggests that the implementation of telecommuting in Mexico, can allow us an area of opportunity, not only for a work style, but also to be able to face crisis situations, such as the pandemic of Covid-19, where the worker stays at home working as a healthier alternative, since in the usual office and the displacement to this, would be more exposed to a contagion that would affect his/her health or life and that of his/her family, and therefore will be workers under less stress and less exposed to adverse situations and, this leads to higher productivity.

Our research involves a very important step to put special emphasis on telecommuting in the organizational culture and in the Mexican labor context. We must be clear that culture has an important influence on human resources management, on the company's practices and operations, job satisfaction and performance of its tasks. What was found provides the academic readers, researchers. and managers a foundation on the environment related to telecommuting, as apply it in Mexican SME companies.

In future research it is necessary to develop comprehensive proposals in order to ensure that companies incorporate telecommuting in their strategic plans and organizational culture. Also other issues that should be researched in detail, so that it does not become a limitation of telecommuting, would be the risks related to the physical and psychological work environment and the possible risks of isolation and increased workload, analyze whether there is a balance between work and personal life that does not threaten the life quality of people.

\section{ACKNOWLEDGEMENT}

Translated \& Edited by American Publishing Services (https://americanpublishingservices.com/).

\section{ENDNOTE}

1. The Guadalajara Metropolitan Area, as established by INEGI in 2010, is located in the central part of the Jalisco State and is officially made up of eight municipalities of which six are considered central and two are considered outer, the eight municipalities are: San Pedro Tlaquepaque, Tonalá, Zapopan, Tlajomulco de Zúñiga, El Salto, Juanacatlán, Ixtlahuacan de los Membrillos and Guadalajara.

\section{REFERENCES}

Agudo Moreno, M.J. (2014). El teletrabajo en las organizaciones: Análisis de sus beneficios y barreras en las empresas españolas. Cuadernos De Gestión De Información, 4, 172-187. Retrieved from https://revistas.um.es/gesinfo/article/view/221801

Beham, B., Baierl, A., \& Poelmans, S. (2015). Managerial telework allowance decisions-A vignette study among German managers. The International Journal of Human Resource Management, 26(11), $1385-1406$.

Camargo, R. (2020, March 30). Capacidades para teletrabajo en la Crisis Pandémica en México. The Competitive Intelligence Unit. Retrieved from https://www.theciu.com/publicaciones2/2020/3/30/capacidades-para-teletrabajo-en-la-crisis-pandmica-en-mxico

Cárcamo Ulloa, L., \& Muñoz Villegas, O. (2009). Competencias comunicativas y actitud hacia el teletrabajo de estudiantes universitarios chilenos. Revista Latina de Comunicación Social, 64, 802-809. https://doi.org/10.4185/RLCS-64-2009-862-802-809

Cicei, C. (2015). Managing the Work and Family Roles. Does Flexibility Reduce the Negative Interference? An Exploratory Study. Management Dynamics in the Knowledge Economy, 3(4), $717-727$. 
Cifuentes Leiton, D.M., \& Giraldo Tamayo, A.L. (2017). Implicaciones psicosociales del teletrabajo sobre el teletrabajador. Versiones desde actores: Gobierno, empleadores y teletrabajadores. In E. Renteria Pérez \& M. Sigmar (Eds.), Temas e Investigaciones en Psicología Organizacional y del Trabajo (1ra. Edición, pp. 163-182). Cali, Colombia, Universidad del Valle.

Davies, R. (2013, May 27). Work-Life Balance Measures to Help Reconcile Work, Private and Family Life. Biblioteca de Parlamento Europeo. Retrieved from http://www.europarl.europa.eu/RegData/ bibliotheque/briefing/2013/130549/LDM_BRI(2013)130549 REV1_EN.pdf

Díaz, L.G. (2002). Estadística Multivariada: Inferencias y Métodos. Bogotá: Universidad Nacional de Colombia

García, V., \& Martínez, R. (2016). Ausentismo laboral y salud: Estudio de su importancia en el teletrabajo. Retos: Revista de Ciencias Administrativas y Económicas, 6(11), 13-25.

Giniger, N. (2020). Teletrabajo. Modalidad de trabajo en pandemia. Revista Observatorio Latinoamericano y Caribeño, 1(4), 24-39. Retrieved from https://publicaciones.sociales.uba.ar/ index.php/observatoriolatinoamericano/article/view/5451/4850

Guzmán Duque, A.P., \& Abreo Villamizar, C.A. (2017). Las habilidades del teletrabajador para la competitividad. Forum Empresarial, 22(2), 5-30. Retrieved from https://www.redalyc.org/articulo.oa?id=631/63154910002

Hernández Sampieri, R., Fernández Collado, C., \& Baptista Lucio, P. (2014). Metodología de la Investigación ( $6^{\mathrm{a}}$ edición). México: McGraw Hill.

Instituto Nacional de estadística y Geografía, INEGI. (2019). Datos. Censos Económicos 2019. Retrieved from https://www.inegi.org.mx/programas/ce/2019/

Kundaragi, P., \& Kadakol, A. (2015). Work Stress of Employee: A Literature Review. International Journal of Humanities and Social Science Research, 1(1), 4-7.

Lind, D., Marchal, W., \& Wathen, S. (2015). Estadística aplicada a los negocios y la economía. México: McGraw-Hill.

Madero Gómez, S.M., \& Flores Zambada, R. (2009). Predictores de la disposición de trabajadores mexicanos a aceptar el teletrabajo. Investigación y Ciencia, 17(43), 46-52. Retrieved from https://www.redalyc.org/articulo.oa?id=674/67411387009

Neirotti, P., Raguseo, E., \& Gastaldi, L. (2019). Diseño de prácticas laborales flexibles para la satisfacción laboral: La relación entre las características del trabajo y la desagregación del trabajo en diferentes tipos de arreglos laborales. New Technology, Work and Employment, 34(2), 116138. https://doi.org/10.1111/ntwe.12141

Pearce, J., II. (2009). Successful Corporate Telecommuting with Technology Considerations for Late Adopters. Organ Dyn, 38(1), 16-25. https://dx.doi.org/10.1016/j.orgdyn.2008.10.002

Raffaele, C., \& Connell, J. (2016). Telecommuting and Co-Working Communities: What Are the Implications for Individual and Organizational Flexibility? In C.J. Sushil \& J. Burgess (Eds.), Flexible Work Organizations. Flexible Systems Management. Springer, New Delhi. https://doi.org/10.1007/978-81-322-2834-9_2

Ruíz, F., Gonzales, R., \& Lucendo, A. (2020). La Brecha Digital en la Unión Europea. Modelos Explicativos, Predictivos y Espaciales (CSO2015- 67662-P), financiado por el Ministerio de Economía y Competitividad (2016- 18). ISSN 1989-9890. Alicante - España: Universidad de Alicante. Instituto Interuniversitario de Geografía. https://doi.org/10.14198/INGEO2020.RRGRLM

Tapasco Alzate, O., \& Giraldo García, J. (2016). Factores asociados a la disposición por el teletrabajo entre docentes universitarios. Ciencia \& Trabajo, 18(56), 87-93. https://dx.doi.org/10.4067/S0718-24492016000200003

Zúñiga, A. (2013) ¿Estamos preparados para teletrabajar? Escritura Pública, (83), 70-72. Retrieved from http://www.notariado.org/liferay/c/document_library/get_file?folderId=12092\&name=DLFE112091.pdf 